\title{
PAT: UM AGENTE PEDAGÓGICO ANIMADO PARA INTERAGIR AFETIVAMENTE COM O ALUNO
}

\author{
Patrícia Augustin Jaques \\ Rosa Maria Vicari \\ PPGC - Instituto de Informática \\ Universidade Federal do Rio Grande do Sul - Bloco IV, Av. Bento Gonçalves, 9500 - \\ Porto Alegre - RS - Brazil, +55 0513316 6801, fax +55 0513316 6832, \\ e-mails: \{pjaques, rosa\}@inf.ufrgs.br

\begin{abstract}
Resumo: Este trabalho apresenta um agente pedagógico animado, chamado Pat, que possui o objetivo de fornecer suporte emocional ao aluno: motivando-o e encorajandoo, fazendo-o acreditar em suas próprias habilidades e promovendo um estado de espírito mais positivo no aluno que, de acordo com psicólogos e pedagogos, é melhor para o seu aprendizado. Este suporte do agente, suas táticas afetivas, é expresso através de comportamentos emotivos e mensagens de encorajamento do personagem animado. Para escolher as táticas afetivas adequadas, o agente deve conhecer as emoções do aluno. $\mathrm{O}$ agente proposto infere as seguintes emoções do aluno: alegria/tristeza, satisfação/frustração, raiva/gratidão e vergonha a partir do comportamento observável do aluno, isto é, das ações do aluno na interface do sistema educacional. A inferência das emoções é fundamentada psicologicamente na abordagem cognitiva das emoções. Mais especificamente, nós usamos o modelo OCC o qual é baseado na abordagem cognitiva das emoções e é possível de ser implementado computacionalmente. Devido a natureza dinâmica da informação sobre o estado afetivo do aluno, nós adotamos uma abordagem BDI para implementar o modelo afetivo do usuário e o diagnóstico afetivo. Além disso, em nosso trabalho nós nos beneficiamos da capacidade de raciocínio do BDI para o agente inferir as emoções do aluno.
\end{abstract}

\section{Introdução}

Psicólogos e pedagogos têm destacado a maneira como as emoções afetam a aprendizagem (Goleman, 1995; Piaget, 1989; Vygotsky, 1962). Segundo Piaget (1989), é incontestável o papel perturbador ou acelerador da afetividade na aprendizagem. Boa parte dos alunos que são fracos em matemática falha devido a um bloqueio afetivo. Os trabalhos de Izard (1984) mostram que emoções negativas induzidas no aluno mostram prejudicar o seu desempenho em tarefas cognitivas e emoções positivas possuem um efeito contrário.

Por esta razão, vários sistemas educacionais têm buscado considerar as emoções do aluno através da inferência de emoções, bem como responder emocionalmente a ele, através da geração de emoção, mostrando a riqueza presente na interação afetiva entre aluno e tutor. 
Com o propósito de contribuir aos trabalhos existentes em computação afetiva aplicada à educação, nós propomos um agente pedagógico animado responsável por motivar o aluno, fornecer suporte afetivo e promover emoções positivas no aluno que são mais adequadas ao seu aprendizado (Izard, 1984). Para responder apropriadamente, esse agente infere e modela as seguintes emoções do aluno: satisfação e frustração, alegria e tristeza, gratidão e raiva e vergonha. Uma importante contribuição do trabalho é se beneficiar da capacidade de raciocínio da abordagem BDI (Belief-Desire-Intention) (Bratman, 1990) para inferir as emoções do aluno através de suas ações na interface do sistema usando um modelo psicológico cognitivo: o modelo OCC (Ortony, Clore \& Colllins, 1988). O agente raciocina sobre as ações do aluno e eventos no sistema educacional e para que emoções esses eventos levam de acordo com os objetivos do aluno. Este trabalho se beneficia de trabalhos prévios do nosso grupo de pesquisa em BDI que resultaram na ferramenta X-BDI (Móra, 1999), usada na implementação.

$\mathrm{O}$ agente proposto se chama PAT (Pedagogical and Affective Tutor). Como um caso de estudo, esse agente é implementado como o Agente Mediador da arquitetura multiagente do ambiente de aprendizagem MACES (Andrade et al., 2001). A implementação de sistemas educacionais usando arquiteturas multiagentes tem sido um dos tópicos de estudo do nosso grupo, como mostram os trabalhos de (d'Amico et al., 1998; Giraffa e Vicari, 1998; Silveira e Viccari, 2002).

Nas próximas seções são descritas as etapas necessárias para a inferência das emoções do aluno e concepção do agente pedagógico animado.

Qual mecanismo utilizado para reconhecer as emoções do aluno?

A inferência das emoções do aluno é um passo necessário para adaptar este sistema a sua afetividade. Por exemplo, se o aluno está frustrado com o seu desempenho, ele irá provavelmente desistir de continuar realizando as atividades educacionais propostas. O agente precisa saber que emoções o aluno está sentindo em um dado momento para poder encorajá-lo a continuar suas atividades.

Para poder inferir as emoções do aluno, o agente proposto possui um sensor (software) responsável por identificar as emoções do aluno e armazena estas informações em um modelo afetivo do aluno.

As emoções do aluno podem ser inferidas por vários mecanismos que estão aptos a detectar emoções por voz, expressões faciais, tensão muscular (eletromiograma), condutividade da pele, respiração e pelo seu comportamento observável. Pat infere as emoções do aluno pelo seu comportamento observável, isto é, pelas ações do aluno na interface do sistema. São exemplos de comportamentos observáveis: tempo de execução de uma atividade, sucesso ou falha na execução de um exercício e pedido de ajuda. Nós escolhemos este método porque ele é a forma mais acessível atualmente para o aluno interagir com o sistema. As pessoas podem se sentir desconfortáveis com outros mecanismos, como video-câmeras, e isso pode interferir no reconhecimento (Picard, 2000). Além disso, equipamentos para reconhecimento de emoções do usuário são bastante caros e de difícil utilização. Esta abordagem foi também usada por outros grupos de pesquisa, como mostram os trabalhos de Vicente e Pain (1998) e Martinho (2000).

\section{Como reconhecer as emoções do aluno?}

Como o agente proposto reconhece as emoções do aluno pelo seu comportamento observável, precisamos de uma teoria psicológica que fundamente. A abordagem cognitiva das emoções é adequada, pois ela considera que as emoções são disparadas por uma avaliação cognitiva (chamada appraisal) que um indivíduo faz baseado nos estímulos do mundo e no seu comportamento (Clore e Ortony, 1999; Scherer, 1999). Em especial, nós utilizamos o modelo OCC (Ortony, Clore e Collins, 1988) que é baseado na abordagem cognitiva das emoções e é possível de ser 
implementado computacionalmente, já que ele fornece informações de como construir uma interpretação de uma situação do ponto de vista do usuário e para qual emoção esta interpretação nos leva.

O modelo OCC nos permite inferir até 22 emoções (tais como alegre por outra pessoa, ressentido, alegre com a infelicidade de outra pessoa, piedade, esperança, entre outras). Neste trabalho, nós reconhecemos e modelamos as emoções satisfação e frustração, alegria e tristeza, gratidão e raiva e vergonha.

Segundo o modelo OCC, as emoções alegria e tristeza surgem quando uma pessoa foca na desejabilidade de um evento de acordo com os seus objetivos. O modelo OCC define que alegria ocorre quando uma pessoa está agradada com um evento desejável e tristeza quando está desagradada com o evento indesejável. Por exemplo, para um aluno que tem como objetivo agradar ao professor e aos seus pais, obter uma boa nota é um evento desejável e irá, provavelmente, disparar a emoção alegria. As emoções satisfação e frustração surgem quando uma pessoa tem a confirmação da realização (satisfação) ou confirmação de não realização (frustração) de um evento desejável que esperava que pudesse se realizar. As emoções gratidão e raiva são disparadas quando uma pessoa avalia as ações de outra em relação à interferência na realização de seus objetivos. Uma pessoa possui gratidão em relação a outra quando avalia que a ação da outra pessoa foi boa e teve consequiência positiva para si. Raiva surge quando a ação de alguém é avaliada como censurável e tendo ainda uma consequiência negativa para si. Se a ação avaliada é a própria ação, emoções como vergonha ou orgulho podem ser disparadas. Orgulho surge quando uma pessoa aprova sua própria ação e vergonha em caso contrário.

Então, para reconhecer as emoções, tristeza e alegria por exemplo, é necessário verificar quando um evento do ambiente educacional é desejável ou indesejável (de acordo com os objetivos do aluno) e quando o aluno está agradado porque este evento desejável aconteceu ou desagradado porque um evento indesejável aconteceu. Desta maneira, precisamos definir (1) os eventos que podem acontecer no ambiente educacional, (2) os objetivos do aluno (para saber se os eventos são desejáveis ou não) e a (3) desejabilidade dos eventos (de acordo com os objetivos do aluno) para inferir as emoções do aluno. Nas próximas seções, descrevemos esses passos.

\section{Determinando os Eventos do Ambiente Educacional}

O modelo OCC diz, por exemplo, que as emoções alegria e tristeza são disparadas quando eventos do mundo são avaliados de acordo com a sua desejabilidade em relação aos objetivos do aluno. Assim, um primeiro passo é determinar os eventos do ambiente educacional. Em um ambiente educacional, os eventos do mundo são as situações que podem ocorrer como, por exemplo, aluno realizar um exercício com sucesso, falhar, pedir ajuda ou negar ajuda, entre outros. Neste trabalho nós escolhemos um número limitado de eventos, mas que nos são suficientes para validar a nossa proposta. Nas Tabelas 1 e 2 podemos ver os eventos que ocorrem no ambiente MACES e que são analisados neste trabalho.

$\mathrm{Na}$ Tabela 1 podemos visualizar os eventos que podem disparar as emoções satisfação, frustração, alegria e tristeza. O conteúdo pedagógico é formado por vários itens pedagógicos, por exemplo, um capítulo ou uma seção. Cada capítulo (ou outro item) é composto de um conteúdo pedagógico, exemplos e exercícios. Eles são escolhidos pelo Agente de Diagnóstico ${ }^{1}$. Em cada capítulo, o aluno solicita ao agente para ir ao próximo capítulo ou retornar ao anterior.

\footnotetext{
${ }^{1} \mathrm{O}$ agente de Diagnóstico é um outro agente que compõe a arquitetura multiagente do ambiente educacional onde Pat está inserida: MACES (Andrade et al., 2001). Ele tem o objetivo de realizar o diagnóstico cognitivo e escolher as táticas de scaffold.

V.3 ํㅜ 1 , Maio, 2005
} 
Tabela 1: Eventos que podem Disparar as Emoções Satisfação/Frustração e Alegria/Tristeza.

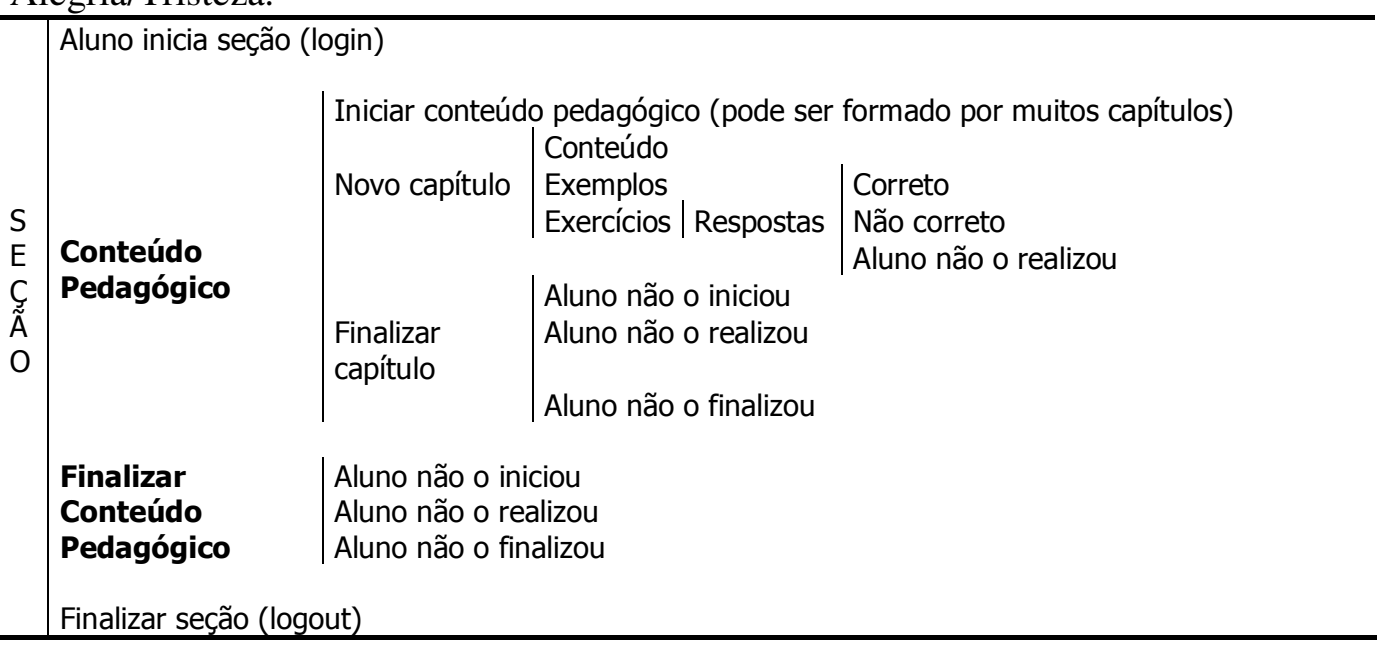

A Tabela 2 mostra os eventos no ambiente educacional que são causados pelo agente e pelo próprio aluno. Quando estes eventos são avaliados pelo aluno, eles podem disparar emoções de raiva ou gratidão em relação ao agente que os causou, neste caso, Pat. Os eventos causados pelo próprio aluno podem disparar a emoção vergonha.

$\mathrm{O}$ aluno pode pedir ajuda ou o agente pode decidir oferecer ajuda ao aluno. Esta ajuda pode ser do tipo específica ou genérica. Uma ajuda genérica fornece exemplos, fórmulas e explanações para um conteúdo pedagógico. A ajuda específica mostra como realizar um exercício. $\mathrm{O}$ aluno pode negar a ajuda do agente, mas o agente sempre fornece ajuda quando o aluno a solicita.

Como o agente é um agente animado com voz artificial, ele pode apresentar comportamentos animados e mensagens de encorajamento ao aluno.

O sistema está disponível na Internet, desta maneira o aluno deve se logar toda vez que desejar acessá-lo.

Tabela 2: Eventos que podem Disparar as Emoções Raiva, Gratidão e Vergonha.

\begin{tabular}{|c|c|c|c|c|}
\hline$A$ & & & & \\
\hline Ç & & Agente oferece ajuda & \multicolumn{2}{|c|}{ Aluno nega ajuda do agente } \\
\hline Õ & & & Aluno aceita & Ajuda Específica \\
\hline$E$ & Ajuda & & & Ajuda Genérica \\
\hline $\begin{array}{l}D \\
\text { O }\end{array}$ & & Aluno pede ajuda & \multicolumn{2}{|c|}{\begin{tabular}{|l} 
Ajuda Específica \\
Ajuda Genérica
\end{tabular}} \\
\hline $\begin{array}{l}A \\
G\end{array}$ & Mensagem & \multicolumn{3}{|c|}{$\begin{array}{l}\text { Agente apresenta uma mensagem de encorajamento ou de motivação ao } \\
\text { aluno }\end{array}$} \\
\hline $\begin{array}{l}\mathrm{E} \\
\mathrm{N} \\
\mathrm{T} \\
\mathrm{E}\end{array}$ & Comportamento & \multicolumn{3}{|c|}{$\begin{array}{l}\text { Agente apresenta uma seqüência de animações. Este comportamento é } \\
\text { usualmente apresentado juntamente com uma mensagem. }\end{array}$} \\
\hline
\end{tabular}

\section{Objetivos do Aluno}

Numa primeira etapa do trabalho, determinamos os eventos que contribuem para a geração de emoções no aluno. Uma segunda etapa é determinar os objetivos do aluno a fim de sabermos se os eventos são desejáveis de acordo com estes objetivos e quando o aluno está agradado/desagradado com a ocorrência ou não destes eventos. 
De acordo com Ames (1990), os alunos podem ter objetivos orientados à aprendizagem ou ao desempenho que são razões pelas quais eles se engajam no seu aprendizado.

Alunos que têm objetivo de aprendizagem são orientados a desenvolver novas habilidades, tentar entender seu trabalho, aperfeiçoar o seu nível e competência e aprender novas coisas. Estes indivíduos tentam fazer mais esforços para aprender algo novo ou quando se defrontam com tarefas desafiantes. Quando eles enfrentam dificuldades, eles aumentam os seus esforços porque acreditam que o esforço é necessário para o sucesso. Eles são chamados também de motivados intrinsecamente.

Os alunos que possuem objetivos de desempenho acreditam que o desempenho é importante e eles querem mostrar que tem capacidade. Eles sentem que obtiveram sucesso quando agradam o professor ou pais ou quando se saem melhores que seus colegas, ao invés de quando aprenderam algo novo. Quando enfrentam dificuldades, eles não aumentam os seus esforços porque isso significa falta de capacidade para eles. Eles também são conhecidos como motivados extrinsecamente.

A orientação motivacional do aluno (extrínseco e intrínseco) é determinada pelo questionário MSLQ (Pintrich, 1991) que é aplicado no início da utilização do sistema pelo aluno.

\section{Desejabilidade dos Eventos}

Nas seções anteriores, vimos como determinar os eventos do ambiente de aprendizagem e os objetivos do aluno, mas ainda precisamos determinar a desejabilidade dos eventos para saber que emoção é disparada. Quando um evento é desejável, ele dispara a emoção alegria; e quando é indesejável dispara a emoção tristeza.

Determinamos a desejabilidade (ou indesejabilidade dos eventos) baseado no que sabemos dos objetivos de alunos orientados à aprendizagem ou ao desempenho, citados por pedagogos, tais como Meece e Mccolskey (2001) e Ames (1990). Quando um evento promove os objetivos do aluno, ele é desejável. Quando ele impede a concretização dos objetivos, ele é indesejável. Por exemplo, para um aluno orientado ao desempenho que tem o objetivo de agradar seus pais, fornecer uma resposta correta para um exercício é um evento desejável porque promove seu objetivo e, pela mesma razão, não fornecer uma resposta correta é um evento indesejável.

\section{Intensidade das Emoções}

Uma emoção tem sempre uma determinada intensidade. De acordo com o modelo OCC, a intensidade das emoções depende de algumas variáveis. A intensidade das emoções tristeza e alegria depende principalmente do quanto o evento é desejável. A intensidade das emoções satisfação e frustração também depende do grau de desejabilidade de um evento, do esforço realizado pelo aluno para a concretização do evento e o grau de realização do evento. A intensidade das emoções gratidão e raiva depende também da desejabilidade do evento. Além disso, a teoria OCC considera que há outros fatores globais (que afetam todas as emoções do modelo OCC) que também devem ser considerados, tais como quanto o evento é inesperado (coisas boas inesperadas são avaliadas mais positivamente que as esperadas).

O grau de desejabilidade de um evento pode ser medido através da informação que temos sobre alunos orientados a performance ou a aprendizagem. Por exemplo, sabemos que alunos orientados a aprendizagem desejam mais fortemente obter uma nota alta. Para medir o esforço do aluno, nós usamos o modelo de esforço de del Soldato (del Soldato \& de Boulay, 1995). O esforço do aluno é inferido através da sua persistência na realização de atividades e nos pedidos de ajuda e pode ter um dos seguintes graus: mínimo, pouco, médio, grande e máximo. A variável realização pode também ser considerada. Por exemplo, quando um aluno motivado extrinsecamente 
deseja obter uma nota ótima para agradar o professor, se ele obter uma nota não tão boa, ele alcança parcialmente o seu objetivo. Para alunos orientados ao desempenho que sempre recebem uma nota mediana, receber uma nota máxima é um evento muito inesperado e por isso dispara emoção satisfação com maior intensidade.

Devido a complexidade de determinar a intensidade das emoções através de alguns indicadores de comportamento observável do aluno, a versão corrente do protótipo identifica somente dois graus de intensidade: médio e alto. Mas, a fim de determinar as emoções disparadas e sua intensidade com maior precisão, o sistema prevê a inserção de sensores fisiológicos, tais como sensores que medem a condutividade da pele e os batimentos cardíacos.

\section{As Emoções do Aluno}

A Tabela 3 mostra as emoções que são disparadas, para cada evento, para os alunos que têm objetivo orientado à aprendizagem e a Tabela 4 apresenta as emoções que são disparadas quando o aluno possui objetivo orientado ao desempenho. Na coluna "eventos" nós apresentamos os eventos que podem acontecer. Uma vez que nós sabemos os objetivos e os eventos, podemos determinar a desejabilidade do evento. Este processo é necessário para inferir o appraisal do aluno, isto é a avaliação cognitiva que dispara as emoções. Cada evento é classificado como desejável (marcado com um D na tabela), indesejável (marcado com um U), ou com nenhuma reação à situação (marcada com um N) na coluna "desejabilidade do evento". Algumas vezes, a fim de determinar se um evento é desejável ou não, o agente necessita fazer perguntas ao aluno ou acessar outro tipo de informação (por exemplo, o esforço do aluno). Estas perguntas são apresentadas na coluna "perguntas do agente". Na coluna "respostas do aluno", as respostas possíveis dadas pelo aluno são apresentadas. A coluna "variáveis de intensidade" descreve as variáveis que afetam a intensidade de cada emoção e, finalmente, a coluna "emoções" apresenta as emoções disparadas. As emoções podem ser tristeza ou alegria, frustração (marcado com Frust) ou satisfação (marcada com Satisf), gratidão ou raiva, e vergonha.

Ainda, para as emoções satisfação e frustração, é necessário saber quando o evento é esperado se realizar ou não. A maioria dos eventos educacionais pode disparar emoções de satisfação e frustração porque são esperados. Por exemplo, quando o aluno realiza um exercício, ele espera obter uma boa nota ou não. Quando o aluno está agradado, em intensidade suficiente, porque um evento desejável e previsto aconteceu, ele sente a emoção satisfação. Quando está desagradado porque o evento desejável não aconteceu, ele tem a emoção frustração. Às vezes, o aluno pode ver um evento indesejável como um evento desejável e previsto que não aconteceu. Este é o exemplo do evento "o aluno não forneceu uma resposta correta para um exercício". Se o evento "fornecer uma resposta correta para o exercício" for um evento muito desejável e previsto, o aluno pode interpretar o evento "o aluno não forneceu uma resposta correta para um exercício" como um evento desejável que não aconteceu e assim é disparada a emoção frustração. As emoções do aluno que são disparadas para cada evento são mostradas na coluna "emoções".

A satisfação e a frustração, a alegria e a tristeza, e as emoções da raiva e gratidão têm valência opostas. $\mathrm{O}$ aluno não pode experimentar frustração e satisfação ao mesmo tempo. Desta maneira, quando o aluno tem a emoção frustração, a emoção de satisfação morre. Como o agente tem como objetivo promover um estado de espírito positivo no aluno, ele age a fim de cancelar as emoções negativas do aluno. Assim, nós consideramos que as intervenções do agente sempre anulam as emoções negativas do aluno. 


\section{Emoções Disparadas quando o Aluno Possui Objetivo Orientado à Aprendizagem}

Os eventos 1,2 e 3 , mostrados na Tabela 3 , dizem respeito à realização das tarefas pelos alunos que têm objetivo orientado à aprendizagem. Se o aluno realizar a tarefa incorretamente ou não a terminar (eventos 1 e 3), é necessário saber se é importante para ele aprender sobre o assunto pedagógico relacionado à tarefa, já que os alunos orientados à aprendizagem são motivados a aprender aqueles assuntos que eles acham interessantes. Se possuir o objetivo de aprender esse assunto, o evento é indesejável. Quando o evento é indesejável, as emoções disparadas são tristeza e frustração. A intensidade destas emoções depende do grau de realização do evento, do grau de expectativa de que o evento aconteça, e também da desejabilidade evento. A variável de realização pode ser determinada pela nota obtida pelo aluno no exercício. $\mathrm{O}$ grau de realização é mais elevado, se a resposta for $70 \%$ incorreta, do que quando a resposta for $50 \%$ incorreta e, assim, o aluno fica mais frustrado na primeira situação. Nós consideramos que o grau de realização é mais forte para as respostas em que o grau de incorreção é superior a 50\%. O grau de não expectativa pode ser medido pelo desempenho real do aluno. O evento "não fornecer uma resposta correta para um exercício" é mais inesperado quando o aluno está tendo um desempenho excelente. Nós consideramos que quando uma ou mais destas variáveis têm um grau mais elevado, uma emoção com uma intensidade mais elevada é disparada (marcado com um ++).

Se o aluno realizou a tarefa corretamente, que é um evento desejável, é importante saber se ele fez um esforço elevado (evento 2). Os alunos com objetivo de aprendizagem tornam-se mais satisfeitos com os resultados bons obtidos nas tarefas que fizeram mais esforços. O grau de realização e de não-expectativa interfere também. É necessário verificar a nota obtida (se elevada, é mais alta a intensidade das emoções satisfação/alegria) e a não expectativa (se o aluno obtém sempre notas boas).

Um assunto pedagógico é composto de capítulos (seções do estudo). Se o aluno terminar o capítulo (evento 5), quando fez todas as tarefas e seguiu todo o índice apresentado, o evento é desejável e dispara emoções de satisfação/alegria. Se ele desistiu ou não obteve uma nota boa (o evento 4), o evento é indesejável. Neste caso é também necessário verificar o grau de realização (nota) e a não expectativa do evento. O grau de desejabilidade pode também ser medido pela interferência deste evento na nota final do curso.

Quando o aluno pede ajuda (evento 7), é importante saber se a ajuda foi adequada para o aluno, assim nós temos um evento desejável, caso contrário o evento é indesejável. $\mathrm{O}$ ato de pedir ajuda (o evento 6) é um evento sem reação afetiva para o aluno orientado à aprendizagem.

Se o aluno aceitar a ajuda do agente (evento 9), a proposta é um evento desejável e o aluno tem a emoção gratidão. Quando o aluno negar a proposta de ajuda do agente (evento 8), não há reação afetiva. Mas, se o agente oferecer ajuda muitas vezes e o aluno não a necessitar, o agente pode estar perturbando o aluno. Assim, este evento transforma-se em um evento indesejável e o aluno sente a emoção raiva.

Se o aluno desabilitar o personagem PAT (evento 10), isso significa que a presença do personagem é indesejável e que o aluno tem raiva do agente. Quando o aluno habilita o personagem (evento 11), as ações do agente são desejáveis porque o aluno pensa que o agente é útil e que pode o ajudar. Neste último caso, o aluno sente a emoção gratidão. Note que nestas últimas situações (eventos 6 a 11), o aluno foca no personagem como um agente dos eventos e neste caso ele têm emoções relacionadas ao julgamento de ações de uma pessoa (raiva e gratidão). 
Tabela 3: Emoções Disparadas quando o Aluno possui Objetivo Orientado à Aprendizagem

\begin{tabular}{|c|c|c|c|c|c|c|}
\hline \multicolumn{7}{|c|}{$\begin{array}{c}\text { Aluno possui Objetivo orientado à Aprendizagem } \\
\text { Objetivo do Aluno: aprender o conteúdo }\end{array}$} \\
\hline \multicolumn{2}{|c|}{ Evento } & Questões do Agente & $\begin{array}{l}\text { Resp. } \\
\text { Alun }\end{array}$ & $\begin{array}{l}\text { Desejab. } \\
\text { Evento }\end{array}$ & $\begin{array}{l}\text { Variáveis de } \\
\text { Intensidade }\end{array}$ & $\begin{array}{l}\text { Emoções do } \\
\text { Aluno }\end{array}$ \\
\hline \multirow[t]{2}{*}{$\mathbf{1}$} & \multirow{2}{*}{$\begin{array}{l}\text { Aluno forneceu } \\
\text { uma resposta } \\
\text { incorreta para } \\
\text { o exercício }\end{array}$} & \multirow{2}{*}{$\begin{array}{l}\text { perguntar ao aluno se é } \\
\text { importante para ele } \\
\text { aprender o conteúdo } \\
\text { relacionado a tarefa. }\end{array}$} & Sim & $\mathrm{U}$ & $\begin{array}{l}\text { realização } \\
\text { não expectativa }\end{array}$ & Tristeza/Frust \\
\hline & & & Não & $\mathrm{N}$ & & NE \\
\hline \multirow[t]{2}{*}{2} & \multirow{2}{*}{$\begin{array}{l}\text { Aluno forneceu } \\
\text { uma resposta } \\
\text { correta para o } \\
\text { exercício }\end{array}$} & \multirow[t]{2}{*}{ esforço } & Alto & $\mathrm{D}$ & \multirow{2}{*}{$\begin{array}{l}\text { realização } \\
\text { não expectativa }\end{array}$} & Alegria/Satisf++ \\
\hline & & & Baixo & $\mathrm{D}$ & & Alegria/Satisf \\
\hline \multirow[t]{2}{*}{3} & \multirow{2}{*}{$\begin{array}{l}\text { Aluno não } \\
\text { realizou a } \\
\text { atividade }\end{array}$} & \multirow{2}{*}{$\begin{array}{l}\text { perguntar ao aluno se é } \\
\text { importante para ele } \\
\text { aprender o conteúdo } \\
\text { relacionado a tarefa. }\end{array}$} & Sim & $\mathrm{U}$ & $\begin{array}{l}\text { realização } \\
\text { não expectativa }\end{array}$ & Tristeza/Frust \\
\hline & & & Não & $\mathrm{N}$ & & NE \\
\hline \multirow[t]{2}{*}{4} & \multirow{2}{*}{$\begin{array}{l}\text { Aluno desistiu } \\
\text { de seguir o } \\
\text { capítulo }\end{array}$} & \multirow{2}{*}{$\begin{array}{l}\text { perguntar ao aluno se é } \\
\text { importante para ele } \\
\text { aprender o conteúdo } \\
\text { relacionado a tarefa. }\end{array}$} & Sim & $U$ & $\begin{array}{l}\text { realização } \\
\text { não expectativa }\end{array}$ & Tristeza/Frust \\
\hline & & & Não & $\mathrm{N}$ & & NE \\
\hline 5 & $\begin{array}{l}\text { Aluno finalizou } \\
\text { o capítulo }\end{array}$ & & & $\mathrm{D}$ & $\begin{array}{l}\text { realização } \\
\text { não expectativa }\end{array}$ & Alegria/Satisf \\
\hline 6 & $\begin{array}{l}\text { Aluno pediu } \\
\text { ajuda }\end{array}$ & & & $\mathrm{N}$ & & NE \\
\hline \multirow[t]{2}{*}{7} & \multirow{2}{*}{$\begin{array}{l}\text { Após ajuda do } \\
\text { agente }\end{array}$} & \multirow{2}{*}{$\begin{array}{l}\text { perguntar ao aluno se "a } \\
\text { ajuda foi adequada" }\end{array}$} & Sim & $\mathrm{D}$ & & Gratidão \\
\hline & & & Não & $U$ & & Raiva \\
\hline \multirow[t]{2}{*}{8} & \multirow{2}{*}{$\begin{array}{l}\text { Aluno negou } \\
\text { ajuda do } \\
\text { agente }\end{array}$} & \multirow{2}{*}{$\begin{array}{l}\text { perguntar ao aluno se o } \\
\text { agente está o } \\
\text { incomodando }\end{array}$} & Sim & $\mathrm{U}$ & & Raiva \\
\hline & & & Não & $\mathrm{N}$ & & NE \\
\hline 9 & $\begin{array}{l}\text { Aluno aceitou } \\
\text { ajuda do } \\
\text { agente }\end{array}$ & & & $\mathrm{D}$ & & Gratidão \\
\hline 10 & $\begin{array}{l}\text { Aluno } \\
\text { desabilitou o } \\
\text { agente } \\
\end{array}$ & & & $U$ & & Raiva \\
\hline 11 & $\begin{array}{l}\text { Aluno habilitou } \\
\text { o agente }\end{array}$ & & & $\mathrm{D}$ & & Gratidão \\
\hline
\end{tabular}

Emoções Disparadas quando o Aluno Possui Objetivo Orientado ao Desempenho

A Tabela 4 trata das emoções para os alunos que têm objetivo orientado ao desempenho. Para um aluno orientado ao desempenho, o evento "não realizou a tarefa corretamente ou não a terminou" é indesejável (eventos 1 e 3) e dispara as emoções tristeza e frustração. Estes eventos são mais indesejáveis se o aluno realizou um esforço maior e disparam assim emoções com intensidade mais elevada. Se ele realizou a tarefa corretamente, é importante saber se fez esforços (evento 2). Os alunos orientados ao desempenho tornam-se mais satisfeitos pelos bons resultados obtidos nas tarefas em que fizeram menos esforço porque implica em habilidade elevada (Meece e Mccolskey, 2001). Mas, se ele fez esforços, ele espera mais fortemente ter sucesso e, então, o evento dispara uma emoção de intensidade mais elevada, caso isso não aconteça. 
Se o aluno terminar o capítulo com sucesso (evento 5), o evento é desejável e a emoção disparada é alegria/satisfação.

Se o aluno terminar o capítulo sem sucesso ou desistir (evento 4), o evento é indesejável e dispara emoções de tristeza/frustração. A intensidade da emoção depende da variável de realização. Quanto mais elevada a nota, mais elevado o nível de realização e, conseqüientemente, (mais elevada) a intensidade da emoção positiva. Diferentemente, se a emoção for negativa, a intensidade é mais elevada quando o aluno obtém uma nota mais baixa. A variável esforço afeta também a intensidade da emoção. O esforço elevado implica que a intensidade da emoção é mais elevada. A variável não expectativa interfere também na intensidade da emoção. $O$ grau de não expectativa pode ser medido pelo desempenho do aluno. O evento "aluno forneceu uma resposta incorreta para um exercício" é menos esperado quando o aluno está tendo um desempenho excelente. Nós consideramos que quando uma ou mais destas variáveis têm um grau mais elevado, uma emoção com uma intensidade mais elevada é disparada.

Quando o aluno pede ajuda (evento 6), é importante perguntar ao aluno se ele se sente desconfortável ao fazê-lo. Pedir ajuda pode significar para o aluno orientado ao desempenho que ele não é capaz de poder realizar a tarefa sozinho. Se o aluno responder que se sente confortável, não há nenhuma reação afetiva. Se ele se sentir desconfortável, significa que ele desaprova sua atitude de mostrar a Pat que ele não pode realizar as atividades sozinho, e então ele sente vergonha. Se a ajuda não for apropriada (evento 7), o aluno está desagradado, já que o objetivo de receber uma ajuda apropriada pelo agente não se realizou. Neste caso o aluno sente raiva.

Quando o aluno não aceita a ajuda do agente (evento 8), é também importante saber se o aluno está desconfortável com a ajuda e se o agente o está perturbando. Se ele se sente confortável, não é disparada nenhuma emoção, mas se ele se sentir incomodado, o evento é indesejável e o aluno torna-se irritado com o agente, já que o agente oferecer ajuda pode significar ao aluno que o agente está sugerindo que ele não pode realizar a tarefa sozinho. Se o agente estiver perturbando o aluno, o aluno torna-se também irritado com o agente.

Se o aluno aceitar a ajuda do agente (o evento 9), o aluno sente gratidão porque a ajuda do agente foi útil para ele. Se o aluno desabilitar o personagem PAT (evento 10), significa que ele está irritado com o personagem, e porque ele teme o que o agente pensa sobre o seu desempenho. Quando o aluno habilita o personagem (evento 11), ele sente gratidão em relação às ações do agente, e pensa que pode confiar no agente, que ele é engraçado e que pode o ajudar.

Tabela 4: Emoções Disparadas quando o Aluno possui Objetivo Orientado ao Desempenho

\begin{tabular}{l|l|l|l|l|l|l}
\hline \multicolumn{5}{c}{$\begin{array}{c}\text { Aluno possui Objetivo orientado ao Desempenho } \\
\text { Objetivo do Aluno: ter sucesso e obter recompensa }\end{array}$} \\
\hline \multicolumn{1}{|c|}{$\begin{array}{l}\text { Questões do } \\
\text { Agente }\end{array}$} & $\begin{array}{l}\text { Resp. } \\
\text { Alun }\end{array}$ & $\begin{array}{l}\text { Desejab. } \\
\text { Evento }\end{array}$ & $\begin{array}{l}\text { Variáveis de } \\
\text { Intensidade }\end{array}$ & $\begin{array}{l}\text { Emoções do } \\
\text { Aluno }\end{array}$ \\
\hline $\mathbf{1}$ & $\begin{array}{l}\text { Aluno forneceu uma } \\
\text { resposta incorreta } \\
\text { para o exercício }\end{array}$ & & $\mathrm{U}$ & $\begin{array}{l}\text { Realização } \\
\text { não expectativa } \\
\text { esforço } \\
\text { indesejabilidade }\end{array}$ & Tristeza/Frust \\
\hline $\mathbf{2}$ & $\begin{array}{l}\text { Aluno forneceu uma } \\
\text { resposta correta }\end{array}$ & & $\mathrm{N}$ & & NE \\
\hline
\end{tabular}

V.3 No 1, Maio, 2005 


\begin{tabular}{|c|c|c|c|c|c|c|}
\hline & para o exercício & & & $\mathrm{D}$ & $\begin{array}{l}\text { esforço } \\
\text { indesejabilidade }\end{array}$ & Alegria/Satisf \\
\hline \multirow[t]{2}{*}{3} & \multirow{2}{*}{$\begin{array}{l}\text { Aluno não realizou } \\
\text { a atividade }\end{array}$} & & & $\mathrm{U}$ & \multirow{2}{*}{$\begin{array}{l}\text { Realização } \\
\text { não expectativa } \\
\text { esforço } \\
\text { indesejabilidade }\end{array}$} & Tristeza/Frust \\
\hline & & & & $\mathrm{N}$ & & NE \\
\hline \multirow[t]{2}{*}{4} & \multirow{2}{*}{$\begin{array}{l}\text { Aluno desistiu de } \\
\text { seguir o capítulo }\end{array}$} & & $\operatorname{sim}$ & $\mathrm{U}$ & & Tristeza/Frust \\
\hline & & & não & $\mathrm{N}$ & $\begin{array}{l}\text { Realização } \\
\text { não expectativa } \\
\text { esforço } \\
\text { indesejabilidade }\end{array}$ & NE \\
\hline 5 & $\begin{array}{l}\text { Aluno finalizou o } \\
\text { capítulo }\end{array}$ & & & $\mathrm{D}$ & $\begin{array}{l}\text { Realização } \\
\text { não expectativa } \\
\text { esforço } \\
\text { indesejabilidade }\end{array}$ & Alegria/Satisf \\
\hline \multirow[t]{2}{*}{6} & \multirow[t]{2}{*}{ Aluno pediu ajuda } & \multirow{2}{*}{$\begin{array}{l}\text { o aluno se sente } \\
\text { desconfortável por } \\
\text { pedir ajuda }\end{array}$} & $\operatorname{sim}$ & $U$ & $\begin{array}{l}\text { Desprezabilidad } \\
\text { e }\end{array}$ & \multirow[t]{2}{*}{ NE } \\
\hline & & & não & $\mathrm{N}$ & & \\
\hline \multirow[t]{2}{*}{7} & \multirow{2}{*}{$\begin{array}{l}\text { Após ajuda do } \\
\text { agente }\end{array}$} & \multirow{2}{*}{$\begin{array}{l}\text { a ajuda foi } \\
\text { apropriada }\end{array}$} & $\operatorname{sim}$ & $\mathrm{D}$ & & Gratidão \\
\hline & & & não & $\mathrm{U}$ & $\begin{array}{l}\text { Indesejabilidade } \\
\text { Desprezabilidad } \\
\text { e }\end{array}$ & Raiva \\
\hline \multirow[t]{2}{*}{8} & \multirow[t]{2}{*}{$\begin{array}{l}\text { Aluno negou ajuda } \\
\text { do agente }\end{array}$} & \multirow{2}{*}{$\begin{array}{l}\text { o aluno se sente } \\
\text { desconfortável pelo } \\
\text { agente oferecer } \\
\text { ajuda e se o agente } \\
\text { o está incomodando }\end{array}$} & $\operatorname{sim}$ & $U$ & $\begin{array}{l}\text { Indesejabilidade } \\
\text { Desprezabilidad } \\
\text { e }\end{array}$ & Raiva \\
\hline & & & não & $\mathrm{N}$ & & NE \\
\hline 9 & $\begin{array}{l}\begin{array}{l}\text { Aluno aceitou ajuda } \\
\text { do agente }\end{array} \\
\end{array}$ & & & $\mathrm{D}$ & $\begin{array}{l}\text { Desejabilidade } \\
\text { Merecimento }\end{array}$ & Gratidão \\
\hline 10 & $\begin{array}{l}\text { Aluno desabilitou o } \\
\text { agente }\end{array}$ & & & $\mathrm{U}$ & $\begin{array}{l}\text { Indesejabilidade } \\
\text { Desprezabilidad } \\
\text { e }\end{array}$ & Raiva \\
\hline 11 & $\begin{array}{l}\text { Aluno habilitou o } \\
\text { agente }\end{array}$ & & & $\mathrm{D}$ & $\begin{array}{l}\text { Desejabilidade } \\
\text { Merecimento }\end{array}$ & Gratidão \\
\hline
\end{tabular}

\section{Táticas Afetivas de Aprendizagem}

As táticas afetivas são determinadas de acordo com as emoções do aluno, o evento que aconteceu (por exemplo, aluno forneceu uma resposta errada para o exercício) e sua orientação motivacional (orientado ao desempenho ou à aprendizagem). A Figura 1 ilustra os fatores que determinam a seleção das táticas afetivas. 


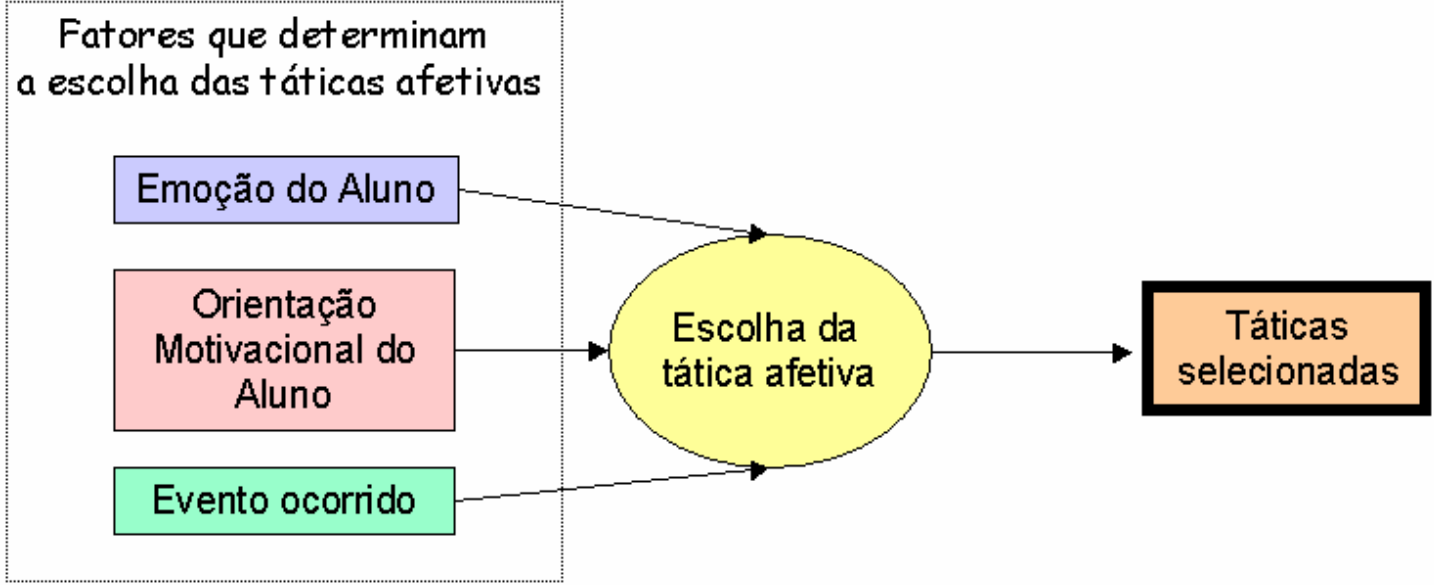

Figura 1: Fatores que Determinam a Escolha das Táticas Afetivas.

A Tabela 5 mostra as táticas afetivas. Cada tática afetiva é composta de um comportamento verbal (o que o agente fala) e um comportamento físico (o que o agente faz) de Pat. Por exemplo, quando o aluno orientado ao desempenho está alegre e satisfeito porque forneceu uma resposta correta ao exercício, Pat apresenta a tática "congratula-aluno". Essa tática é composta pelo comportamento verbal do tipo "congratulação" e o comportamento físico do tipo "congratulação".

As siglas $\mathrm{CV}$ e $\mathrm{CF}$ na tabela representam:

$\mathrm{CV}=$ comportamento verbal (o que o agente fala)

$\mathrm{CF}=$ comportamento físico (o que o agente faz)

Tabela 5: Táticas Afetivas de Apredizagem

\begin{tabular}{|c|c|c|}
\hline Evento & $\begin{array}{c}\text { Motivação Intrínseca } \\
\text { (Objetivos de Aprendizagem) }\end{array}$ & $\begin{array}{c}\text { Motivação Extrínseca } \\
\text { (Objetivos de Desempenho) }\end{array}$ \\
\hline \multirow{4}{*}{$\begin{array}{l}\text { 1) Aluno } \\
\text { forneceu uma } \\
\text { resposta } \\
\text { incorreta para } \\
\text { o exercício }\end{array}$} & Tristeza/Frustração: & Tristeza/Frustração: \\
\hline & $\begin{array}{l}\text { 1) Reconhece-esforço-aluno } \\
\text { CV: Reconhece-esforço-aluno } \\
\text { CF: Empático } \\
\text { 2) Oferece-ajuda } \\
\text { CV: Oferece-ajuda } \\
\text { CF: Fala } \\
\end{array}$ & \multirow{3}{*}{$\begin{array}{l}\text { 1) Aumenta-auto-eficácia-aluno } \\
\text { CV: Aumenta-auto-eficácia-aluno } \\
\text { CF: Encorajamento } \\
\text { 2) Aumenta-esforço-aluno } \\
\text { CV: Aumenta-esforço-aluno } \\
\text { CF: Fala } \\
\text { 3) Oferece-ajuda } \\
\text { CV: Oferece-ajuda } \\
\text { CF: Dá-ajuda }\end{array}$} \\
\hline & NE: & \\
\hline & $\begin{array}{l}\text { Agente aplica tática sugerida pelo Agente } \\
\text { de Diagnóstico }\end{array}$ & \\
\hline \multirow{2}{*}{$\begin{array}{l}\text { 2) Aluno } \\
\text { forneceu uma } \\
\text { resposta } \\
\text { correta para o } \\
\text { exercício }\end{array}$} & Alegria/Satisfação: & Alegria/Satisfação: \\
\hline & $\begin{array}{l}\text { 1) Congratula-aluno } \\
\text { CF: Congratulação (moderada) } \\
\text { CV: Congratulação (moderada) } \\
\text { 2) Mostra-aluno-novas-habilidades- } \\
\text { adquiridas } \\
\text { CV: Nova-habilidade } \\
\text { CF: Nova-habilidade } \\
\end{array}$ & $\begin{array}{l}\text { 1) Congratula-aluno } \\
\text { CF: Congratulação } \\
\text { CV: Congratulação }\end{array}$ \\
\hline \multirow{2}{*}{$\begin{array}{l}\text { 3) Aluno não } \\
\text { realizou a } \\
\text { atividade }\end{array}$} & Tristeza/Frustração: & Tristeza/Frustração: \\
\hline & $\begin{array}{l}\text { 1) Encoraja-aluno } \\
\text { CV: Encorajamento } \\
\text { CF: Encorajamento } \\
\text { 2) Oferece-ajuda } \\
\text { CV: Oferece-ajuda } \\
\text { CF: Dá-ajuda }\end{array}$ & $\begin{array}{l}\text { 1) Aumenta-auto-eficácia-aluno } \\
C V \text { : Aumenta-auto-eficácia-aluno } \\
\text { CF: Encorajamento } \\
\text { 2) Aumenta-esforço-aluno } \\
\text { CV: Aumenta-esforço-aluno } \\
\text { CF: Fala }\end{array}$ \\
\hline
\end{tabular}


NE:

1) Mostra-aluno-novas-habilidadesadquiridas

CV: Nova-habilidade

CF: Nova-habilidade

2) Oferece-ajuda

CV: Oferece-ajuda

CF: Dá-ajuda

\begin{tabular}{|c|c|c|}
\hline \multirow{6}{*}{$\begin{array}{l}\text { 4) Aluno } \\
\text { desistiu de } \\
\text { seguir o } \\
\text { capítulo }\end{array}$} & NE: & NE: \\
\hline & $\begin{array}{l}\text { 1) Mostra-curiosidade-sobre-assunto } \\
\text { CV: Mostra-curiosidade } \\
\text { CF: Mostra-curiosidade }\end{array}$ & \multirow{3}{*}{$\begin{array}{l}\text { Se (esforço-aluno != alto) } \\
\text { 1) Aumenta-esforço-aluno } \\
\text { CV: Aumenta-esforço-aluno } \\
\text { CF: Encorajamento. } \\
\text { Senão } \\
\text { 1) Encoraja-aluno } \\
\text { CV: Encorajamento } \\
\text { CF: Encorajamento }\end{array}$} \\
\hline & Tristeza/Frustração: & \\
\hline & \multirow{3}{*}{$\begin{array}{l}\text { 1) Encoraja-aluno } \\
\text { CV: Encorajamento } \\
\text { CF: Fala } \\
\text { 2) Oferece-ajuda } \\
\text { CV: Oferece-ajuda } \\
\text { CF: Dá-ajuda }\end{array}$} & \\
\hline & & Tristeza/Frustração: \\
\hline & & $\begin{array}{l}\text { Se (esforço-aluno != alto) } \\
\text { 1) Aumenta-auto-eficácia-aluno } \\
\text { CV: Aumenta-auto-eficácia-aluno } \\
\text { CF: Encorajamento } \\
\text { 2) Aumenta-esforço-aluno } \\
\text { CV: Aumenta-esforço-aluno } \\
\text { CF: Fala } \\
\text { Senão se (esforço-aluno == alto) } \\
\text { 1) Aumenta-auto-eficácia-aluno } \\
\text { CV: Aumenta-auto-eficácia-aluno } \\
\text { CF: Encorajamento } \\
\text { 2) Encoraja-aluno } \\
\text { CV: Encorajamento } \\
\text { CF: Fala }\end{array}$ \\
\hline \multirow{2}{*}{$\begin{array}{l}\text { 5) Aluno } \\
\text { finalizou o } \\
\text { capítulo }\end{array}$} & Alegria/Satisfação: & Alegria/Satisfação: \\
\hline & $\begin{array}{l}\text { 1) Congratula-aluno } \\
\text { CF: Congratulação } \\
\text { CV: Congratulação }\end{array}$ & $\begin{array}{l}\text { 1) Congratula-aluno } \\
\text { CF: Congratulação } \\
C V \text { : Congratulação }\end{array}$ \\
\hline \multirow{4}{*}{$\begin{array}{l}\text { 6) Aluno } \\
\text { pediu ajuda }\end{array}$} & NE: & Vergonha: \\
\hline & \multirow[t]{3}{*}{$\begin{array}{l}\text { 1) Dá-ajuda } \\
\text { CV: Dá-ajuda } \\
\text { CF: Dá-ajuda }\end{array}$} & $\begin{array}{l}\text { 1) Explica-importância-ajuda } \\
\text { CV: Explica-importância-ajuda } \\
\text { CF: Empático } \\
\text { 2) Dá-ajuda } \\
\text { CV: Dá-ajuda } \\
\text { CF: Dá-ajuda }\end{array}$ \\
\hline & & NE: \\
\hline & & $\begin{array}{l}\text { 1) Dá-ajuda } \\
\text { CV: Dá-ajuda } \\
\text { CF: Dá-ajuda }\end{array}$ \\
\hline \multirow{4}{*}{$\begin{array}{l}\text { 7) Após ajuda } \\
\text { do agente }\end{array}$} & Raiva: & Raiva: \\
\hline & $\begin{array}{l}\text { 1) Agente-está-triste-por-não-ajudar } \\
\text { CV: Triste-por-não-ajudar. } \\
\text { CF: Triste. } \\
\text { 2) Informa ao Agente de Diagnóstico que a } \\
\text { ajuda não foi apropriada }\end{array}$ & $\begin{array}{l}\text { 1) Agente-está-triste-por-não-ajudar } \\
\text { CV: Triste-por-não-ajudar. } \\
\text { CF: Triste. } \\
\text { 2) Informa ao Agente de Diagnóstico que a } \\
\text { ajuda não foi apropriada }\end{array}$ \\
\hline & Gratidão: & NE: \\
\hline & $\begin{array}{l}\text { 1) Agente-está-alegre-por-ajudar- } \\
\text { student } \\
\text { CV: Alegre-por-ajudar } \\
\text { CF: Alegre-por }\end{array}$ & $\begin{array}{l}\text { 1) Agente-está-alegre-por-ajudar- } \\
\text { student } \\
\text { CV: Alegre-por-ajudar } \\
\text { CF: Alegre-por }\end{array}$ \\
\hline
\end{tabular}




\begin{tabular}{|c|c|c|}
\hline \multirow{2}{*}{$\begin{array}{l}\text { 8) Aluno } \\
\text { negou ajuda } \\
\text { do agente }\end{array}$} & Raiva: & Raiva: \\
\hline & $\begin{array}{l}\text { se (agente_está_atrapalhando) } \\
\text { 1) Triste-por-atrapalhar } \\
\text { CV: Triste-por-atrapalhar } \\
\text { CF: Triste }\end{array}$ & $\begin{array}{l}\text { se (agente_está_atrapalhando) } \\
\text { 1) Triste-por-atrapalhar } \\
\text { CV: Triste-por-atrapalhar } \\
\text { CF: Triste } \\
\text { senão se (aluno_sente_descnfortável) } \\
\text { 1) Explica-importância-ajuda } \\
\text { CV: Explica-importância-ajuda } \\
\text { CF: Empático } \\
\text { 2) Oferece-ajuda } \\
\text { CV: Oferece-ajuda } \\
\text { CF: Dá-ajuda }\end{array}$ \\
\hline \multirow{2}{*}{$\begin{array}{l}\text { 9) Aluno } \\
\text { aceitou ajuda } \\
\text { do agente }\end{array}$} & Gratitude: & Gratitude: \\
\hline & $\begin{array}{l}\text { 1) Dá-ajuda } \\
\text { CV: Dá-ajuda } \\
\text { CF: Dá-ajuda }\end{array}$ & $\begin{array}{l}\text { 1) Dá-ajuda } \\
\text { CV: Dá-ajuda } \\
\text { CF: Dá-ajuda }\end{array}$ \\
\hline \multirow{2}{*}{$\begin{array}{l}\text { 10) Aluno } \\
\text { desabilitou o } \\
\text { agente }\end{array}$} & Raiva: & Raiva: \\
\hline & $\begin{array}{l}\text { 1) Aluno-desabilita-agente } \\
\text { CV: Aluno-desabilita-agente } \\
\text { CF: Triste }\end{array}$ & $\begin{array}{l}\text { 1) Aluno-desabilita-agente } \\
C V \text { : Aluno-desabilita-agente } \\
\text { CF: Triste }\end{array}$ \\
\hline \multirow{2}{*}{$\begin{array}{l}\text { 11) Aluno } \\
\text { habilitou } 0 \\
\text { agente }\end{array}$} & Gratitude: & Gratitude: \\
\hline & $\begin{array}{l}\text { 1) Aluno-habilita-agente } \\
\text { CV: Aluno-habilita-agente } \\
\text { CF: Alegre-por }\end{array}$ & $\begin{array}{l}\text { 1) Aluno-habilita-agente } \\
\text { CV: Aluno-habilita-agente } \\
\text { CF: Alegre-por }\end{array}$ \\
\hline $\begin{array}{l}\text { 12) Enquanto } \\
\text { o aluno está } \\
\text { realizando } \\
\text { uma atividade }\end{array}$ & $\begin{array}{l}\text { 1) Agente-observa-aluno } \\
\text { CV: Agente-observa-aluno } \\
\text { CF: Agente-observa-aluno } \\
\text { 2) Mostra-curiosidade-sobre-assunto } \\
\text { CV: Mostra-curiosidade } \\
\text { CF: Mostra-curiosidade }\end{array}$ & $\begin{array}{l}\text { 1) Agente-observa-aluno } \\
\text { VB : Agente-observa-aluno } \\
\text { PV : Agente-observa-aluno } \\
\text { 2) Encoraja-aluno } \\
\text { CV: Encorajamento } \\
\text { CF: Fala }\end{array}$ \\
\hline $\begin{array}{l}\text { 13) Aluno fez } \\
\text { grande } \\
\text { esforço para } \\
\text { uma atividade }\end{array}$ & $\begin{array}{l}\text { 1) Reconhece-esforço-aluno } \\
\text { CV: Reconhece-esforço-aluno } \\
\text { CF: Empático }\end{array}$ & $\begin{array}{l}\text { 1) Reconhece-esforço-aluno } \\
\text { CV: Reconhece-esforço-aluno } \\
\text { CF: Reconhece-esforço-aluno } \\
\text { 2) Encoraja-aluno } \\
\text { CV: Encorajamento } \\
\text { CF: Fala }\end{array}$ \\
\hline $\begin{array}{l}\text { 14) Aluno é } \\
\text { ocioso }\end{array}$ & $\begin{array}{l}\text { 1) Aluno-ocioso } \\
\text { CV: Ocioso. } \\
\text { CF: Ocioso. } \\
\text { 2) Mostra-curiosidade-sobre-assunto } \\
\text { CV: Mostra-curiosidade } \\
\text { CF: Mostra-curiosidade }\end{array}$ & $\begin{array}{l}\text { 1) Aluno-ocioso } \\
\text { CV: Ocioso } \\
\text { CF: Ocioso } \\
\text { 2) Aumenta-esforço-aluno } \\
\text { CV: Aumenta-esforço-aluno } \\
\text { CF: Fala }\end{array}$ \\
\hline
\end{tabular}

Quando o aluno que possui orientação intrínseca se sente frustrado porque ele não realizou a tarefa corretamente (evento 1), o agente apresenta uma expressão facial empática mostrando que ele entende as dificuldades que o aluno está tendo. Como o aluno intrínseco geralmente faz grandes esforços, o agente oferece uma ajuda ao aluno. O tipo da ajuda (especifica ou genérica) é fornecido pelo Agente de Diagnóstico. O aluno que possui motivação extrínseca, sente que ele não é capaz de realizar a atividade proposta quando ele falha. Geralmente não faz muitos esforços quando tem dificuldades porque realizar mais esforços significa falta de competência para ele. $O$ agente apresenta uma mensagem para aumentar as crenças do aluno sobre a sua competência e diz para o aluno que ele é capaz de realizar a tarefa com um pouco mais de esforço. A idéia é mostrar para o aluno com motivação extrínseca que se ele não teve sucesso na atividade, isso não significa falta de competência, mas que ele pode obter resultados melhores com mais esforço.

Quando o aluno que tem motivação intrínseca está satisfeito porque ele cumpriu uma tarefa que lhe interessava com sucesso (evento 2), o tutor mostra qual a nova habilidade que foi adquirida, uma vez que o aluno está motivado para aprender novas V.3 $\mathrm{N}^{\circ}$ 1, Maio, 2005 
coisas. O aluno que tem motivação extrínseca sempre está satisfeito pelo sucesso nas tarefas, uma vez que ele pensa que isto comprova a sua competência. Nestes casos, o agente o parabeniza fortemente por seu desempenho a fim de manter a sua motivação, desde que tais alunos precisam da aprovação de seu tutor.

Uma vez que alunos que têm orientação intrínseca usualmente fazem grandes esforços, o fato de eles não cumprirem uma tarefa (evento 3) não significa falta de esforço, mas uma dificuldade para efetuá-la. Por isso o tutor apresenta uma mensagem de incentivo para que o aluno continue se empenhando, bem como uma ajuda para auxiliar o aluno a superar suas dificuldades. Quando um aluno intrinsecamente motivado está emocionalmente indiferente (ele não está nem satisfeito nem desmotivado, pois acredita que o tema não é importante nem interessante), o tutor lhe apresenta a nova habilidade que poderá adquirir com o tal tema para motivá-lo, bem como uma ajuda específica para lhe ajudar a continuar na solução do problema. $\mathrm{O}$ aluno orientado ao desempenho se decepciona quando não termina uma tarefa, pois avalia isso como uma falta de competência. Nesse caso o agente apresenta uma mensagem com a finalidade de aumentar a sua auto-eficácia (a imagem que ele tem de si próprio, de suas competências), uma vez que as crenças do aluno que dizem respeito a sua competência diminuíram com o fracasso. $\mathrm{O}$ tutor também tenta incentivar o aluno a fazer mais esforço, pois estes alunos se esforçam menos, já que associam esforço à falta de competência da parte deles. Caso o aluno não esteja decepcionado, é que ele não achou o assunto interessante; neste caso o agente destaca as curiosidades do assunto. Brewster e Farger (2000) sugerem que apresentar as curiosidades de um assunto que sejam relevantes à vida do aluno é uma tática eficiente para motivá-lo.

Quando um aluno intrínseco desiste de finalizar um capítulo (evento 4), se ele está emocionalmente indiferente, isso significa que ele não está interessado no tema relacionado ao assunto e, nesse caso, o agente apresenta algumas curiosidades sobre o assunto para motivá-lo. Se ele está frustrado, o agente o encoraja a continuar tentando e oferece uma ajuda. Se o aluno extrínseco realizou grande esforço, o agente o encoraja a continuar se esforçando, caso contrário o agente o estimula a se esforçar mais.

Quando os alunos (extrínsecos e intrínsecos) estão contentes porque finalizaram um capítulo com sucesso (evento 5), o agente os congratula.

Quando um aluno pede ajuda (evento 6), o agente oferece ajuda. Se o aluno extrínseco está com vergonha de pedir ajuda porque para ele isso significa falta de competência, o agente explica a importância da ajuda, além de oferecer ajuda.

Após a ajuda (evento 7), se o aluno está com raiva porque a ajuda não foi eficiente, o agente mostra uma mensagem explicando que sente por não ajudar. Se a ajuda foi eficiente o agente diz que está feliz por ajudar.

Se o aluno nega ajuda do agente (evento 8) e ele está com raiva porque o agente o está incomodando, o agente se desculpa por atrapalhar o aluno. Caso o aluno extrínseco está com vergonha e nega ajuda porque se sente desconfortável ao aceitá-la, o agente explica a importância da ajuda e oferece ajuda ao aluno novamente.

Caso o aluno aceita ajuda do agente (evento 9), o agente fornece a ajuda.

Se o aluno desabilita o agente (evento 10), isso significa que ele está zangado com o agente. Neste caso, o agente apresenta uma mensagem explicando que está triste por não poder ajudar o aluno. No ambiente o aluno pode escolher não ter $o$ acompanhamento do agente animado. $\mathrm{O}$ agente pergunta porque o aluno não deseja mais a sua ajuda a fim de saber como poder o ajudar melhor futuramente.

Se o aluno habilita o agente (evento 11), o agente diz para o aluno que está alegre por poder servir ao aluno novamente. 
Enquanto o aluno está realizando uma tarefa (evento 12), o agente o observa. Ele pode ainda mostrar curiosidades ao aluno intrínseco para despertar o seu interesse no assunto, e encorajar o aluno extrínseco a fazer maiores esforços.

Se o aluno fez grandes esforços em uma atividade (evento 13), o agente reconhece os seus esforços e encoraja o aluno extrínseco a manter os seus esforços.

Se o aluno está algum tempo ocioso (evento 14) e é intrínseco, isso pode significar que ele não está achando o conteúdo suficientemente interessante, então nesse caso o tutor mostra uma curiosidade sobre o assunto. Se ele é extrínseco, ele deve estar parado porque a tarefa necessita de mais esforço, assim o tutor o incentiva a fazer mais esforços.

Para cada tática, existem mais de um comportamento possível de ser exibido. Por exemplo, para a tática de congratulação (elogio) o agente pode aplaudir o aluno ou mostrar uma cena em que as pessoas o estão aplaudindo. A idéia é tornar o agente mais credível, ou seja, mais real e não tão robótico (Bates, 1994). Para isso, ele deve ter um número variado de falas e animações para uma mesma situação para que o seu comportamento não seja previsível.

\section{A Arquitetura do Agente}

Figura 2 mostra a arquitetura do Agente Medidor. A arquitetura do agente é dividida em 2 partes: o módulo Corpo (Body) e o módulo Mente (Mind).

O Corpo do agente é responsável por capturar as ações do aluno na interface do sistema, realizar a comunicação com os outros agentes e mostrar os comportamentos animados e mensagens escolhidos pelo módulo Mente. Este módulo foi implementado em Java ${ }^{2}$.

O módulo Mente é responsável por inferir os estados afetivos do aluno a partir de seu comportamento observável e escolher as táticas pedagógicas afetivas de acordo com o modelo afetivo do aluno. Neste trabalho foi utilizada a abordagem BDI (beliefdesire-intention) (Bratman, 1990) para a implementação da mente do agente (responsável pela inferência das emoções do aluno e escolha das táticas afetivas) e para a implementação do modelo afetivo. A abordagem BDI é baseada em descrever o processamento interno do agente através de estados mentais (crenças, desejos e intenções) e definir a arquitetura de controle que racionalmente seleciona o curso de ações do agente (Giraffa, 1999). Para a modelagem e implementação em BDI da mente, utilizamos a ferramenta X-BDI desenvolvida em nosso grupo de pesquisa pela tese de Michael Móra (Móra, 1998). A abordagem BDI foi escolhida por apresentar algumas vantagens: permite a implementação em uma linguagem de altíssimo nível e permite tratar a dinamicidade das emoções, pois comporta freqüente revisão e modificação das informações sobre o aluno (Bercht e Vicari, 2000). Mais informações sobre o uso da abordagem BDI para a inferência de emoções pode ser encontrado no artigo (Jaques e Vicari, 2004).

Como a mente do agente foi implementada em BDI (mais especificamente em Prolog) e o corpo em Java, foi implementada uma interface de comunicação entre esses dois módulos.

Durante todo o tempo, Pat observa o aluno a fim de capturar dados que serão usados para inferir os estados afetivos do aluno. Estes dados são capturados por sensores que compõem o módulo de Percepção (Perception). Alguns exemplos de sensores são: ferramentas para observar respiração e ritmo cardíaco. Em nosso protótipo, o agente infere as emoções do aluno a partir de seu comportamento observável; assim o sensor é apenas um software responsável por observar as ações do aluno na interface do sistema.

\footnotetext{
${ }^{2}$ http://java.sun.com V.3 No 1, Maio, 2005
} 


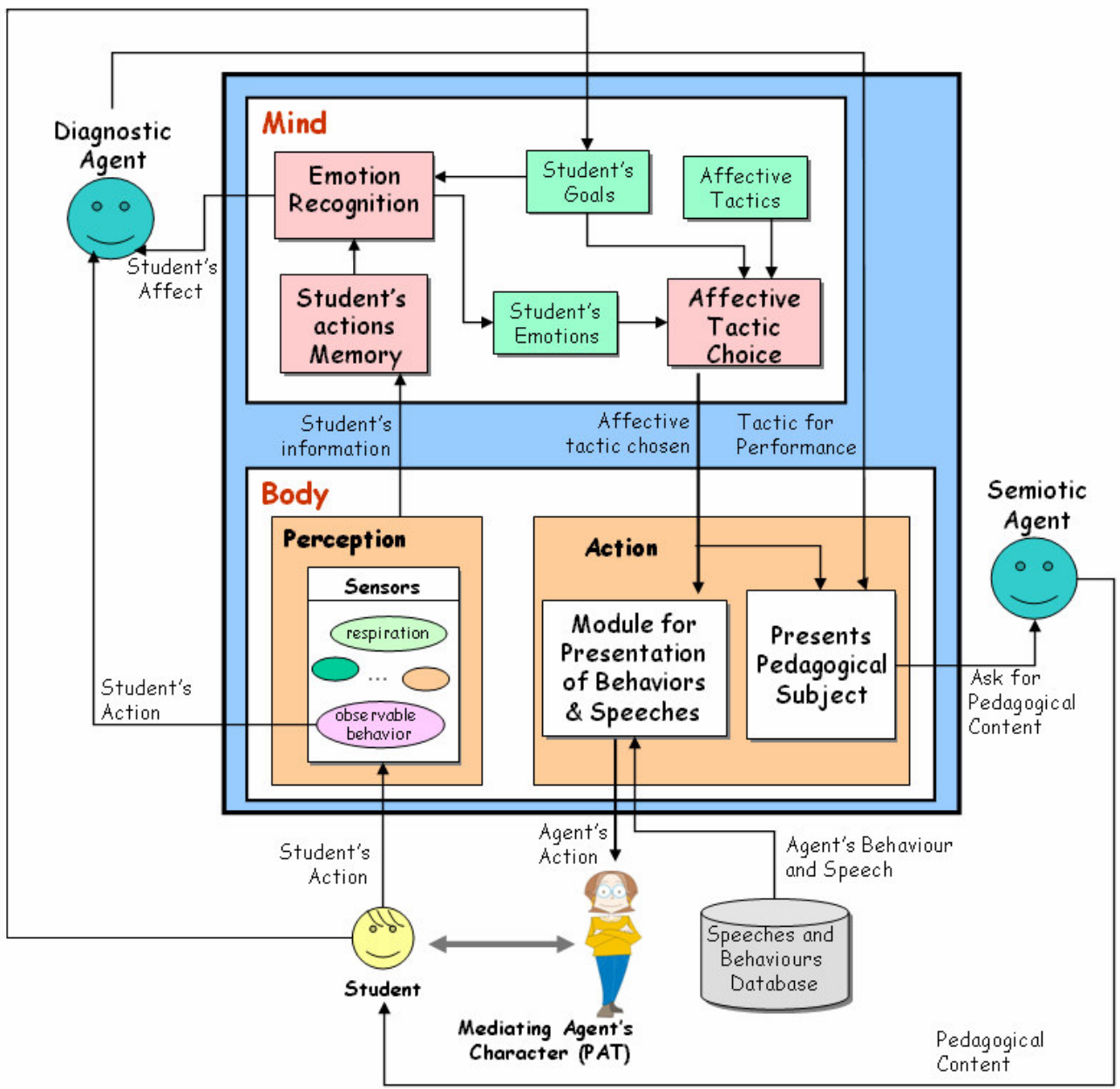

Figura 2: A Arquitetura de Pat

As ações do aluno capturadas pelo módulo de Percepção são enviadas ao Agente de Diagnóstico e ao módulo Mente de Pat. A Mente do agente reconhece as emoções do aluno, atualiza o modelo afetivo e também escolhe as táticas afetivas a serem aplicadas.

Primeiramente, quando a Mente recebe o comportamento observável do aluno, armazena a informação na Memória de Ações do Aluno (Student's Actions Memory) e inicia o processo de reconhecimento das emoções. Algumas vezes, uma emoção é reconhecida através de algum padrão que é formado por um conjunto seqüencial de ações. Desta maneira, é necessário que ações passadas sejam armazenadas no sistema na Memória de Ações Passadas para futura recuperação.

O processo de reconhecimento de emoção verifica se ele pode inferir um estado afetivo a partir da informação recebida (com ou sem ações passadas). As informações recebidas são analisadas de acordo com os objetivos do aluno seguindo o modelo OCC. Se alguma emoção é detectada, ela é mantida no modelo afetivo e se inicia o processo de escolha das táticas afetivas. O estado afetivo do aluno é também enviado ao Agente de Diagnóstico que usará esta informação para melhor definir as habilidades do aluno que estão na ZDP (Andrade; Brna e Viccari, 2002). A tática é enviada ao módulo Ação (Action).

Se a tática afetiva do aluno é a apresentação de um comportamento emocional (por exemplo, congratular o aluno pelo sucesso no exercício), o Módulo de Seleção de Comportamentos e Falas (Module of Selection of Behaviour and Speeches) procura na 
base de dados o comportamento a ser apresentado de acordo com a tática escolhida. Maiores informações sobre esse módulo podem ser encontradas em (Bocca, 2003).

Pat também é responsável por receber as táticas de competência e desempenho do Agente de Diagnóstico. Se a tática é a apresentação de um conteúdo pedagógico, ele faz uma requisição ao Agente Semiótico e exibe o conteúdo ao aluno.

\section{Conclusões e Trabalhos Futuros}

Como observamos nos trabalhos mencionados neste artigo, as emoções possuem um papel importante na aprendizagem e, dessa maneira, não podem ser negligenciadas por professores e ambientes computacionais de ensino. Entretanto, inferir as emoções dos alunos em ambientes computacionais não é uma tarefa simples. Por exemplo, para inferir as emoções nós precisamos de um modelo psicológico de emoções para fundamentar o processo de reconhecimento. O maior desafio está em encontrar um modelo de emoções que possa ser implementado computacionalmente. Neste trabalho nós adotamos o modelo OCC (Ortony, Clore e Collins, 1988) porque foi projetado para ser implementado computacionalmente, ao contrário de outros. Ainda em relação a inferência de emoções, determinar a intensidade das emoções pelo comportamento observável do aluno é uma tarefa difícil e inexata. Nós acreditamos que a inserção de sensores fisiológicos o qual detectam expressões corporais de emoções podem ser utilizados juntamente com a informação inferida através do comportamento observável do aluno (baseado em um modelo cognitivo de emoções) para determinar a intensidade das emoções com mais precisão. Os sensores corporais podem ser útil para identificar quando o aluno está sentindo uma emoção, a valência e a intensidade destas emoções.

Em relação ao modelo afetivo do aluno, este modelo deve ser dinâmico o suficiente para considerar as mudanças no estados emocionais do aluno. Já que a motivação e a afetividade do aluno podem variar de maneira muito dinâmica (o aluno pode se sentir insatisfeito em um dado momento e mais satisfeito em um outro), o uso da abordagem BDI para a implementação de modelos de aluno mostra ser muito conveniente, pois permite simples revisão e freqüente modificação da informação relativa ao aluno (Bercht e Vicari, 2000). O modelo de aluno é construído dinamicamente a partir de cada interação em tempo-real. A abordagem BDI tem sido usada pelo nosso grupo de pesquisa na UFRGS como uma ferramenta para modelagem das habilidades cognitivas do aluno (Giraffa e Vicari, 1998) e também sua motivação (Bercht e Vicari, 2000).

Nós também pretendemos implementar uma versão da Pat independente de plataforma. A tecnologia Flash parece ser uma boa ferramenta para desenhar agentes animados para a web. As falas do agente podem ser gravadas previamente em um formato independente de domínio (como mp3) e podem ser armazenadas como audioclips, em uma base de dados, que serão tocados quando o agente deve falar. Estes audioclips irão resolver o problema de falta de intonação dos sintetizadores de voz, que foi apontado na avaliação deste trabalho.

Nós acreditamos que um trabalho futuro é a extensão do modelo crença-desejointenção (BDI), mais especificamente a ferramenta X-BDI (a ferramenta BDI usada na implementação deste trabalho), a fim de também incluir traços de personalidade, emoções e humor. De acordo com de Rosis (2002), esta abordagem oferece várias vantagens. A primeira é abrir a oportunidade de dirigir comportamentos consistentes do agente a partir do modelo de seu estado cognitivo: o sistema de crenças, desejos e intenções pode disparar as emoções, regular a decisão de quando mostrá-las ou escondêlas e, finalmente, dirigir ações externalizadas. Neste caso, nós estamos incorporando uma arquitetura de emoções (síntese de emoções) no agente para ele gerar comportamento afetivo mais consistente e credível. 
Referências Bibliográficas

C. Ames. Motivation: What Teachers Need to Know. Teachers College Record. 91(3), 409-421, 1990.

A. Andrade et al. A Computational Model of Distance Learning Based on Vygotsky's Sociocultural Approach. In: Workshop Papers: multi-agent architectures for distributed learning environments, 2001.

A. Andrade et al. A Diagnostic Agent based on ZPD approach to improve Group Learning. In: ITS; Workshop on individual and group modelling methods that help learners understand themselves, 2002.

B. J. Bates. The Role of Emotion in Believable Agents. Communications of ACM, New York, v. 37, n. 7, p. 122-125, 1994.

M. Bercht, R. Viccari. Pedagogical agents with affective and cognitive dimensions. In: Proceedings do Congreso Iberoamericnao de Informatica Educativa, Santiago: Universidad de Chile, 2000.

E. Bocca, P. Jaques e R. Viccari. Modelagem e Implementação da Interface para Apresentação de Comportamentos Animados e Emotivos de um Agente Pedagógico Animado. RENOTE - Revista Novas Tecnologias na Educação (ISSN 1679-1916), September/2003, Vol. 1, No 2.

M. E. Bratman. What is intention? In: P. Cohen et al. (Eds.) Intentions in Communication. MIT Press, Cambridge, MA, pages 15-31, 1990.

C. Brewster e J. Fager. Increasing Student Engagement and Motivation: From Time-on-Task to Homework. Portland: Northwest Educational Laboratoty, 2000. Available at: <http://www.nwrel.org/request/oct00/>. Visited on: March 2002.

G. Clore e A. Ortony. Cognition in emotion: always, sometimes, or never? In: L. Nadel et al. (Ed.). The Cognitive Neuroscience of Emotion. New York: Oxford University Press, 1999.

C. D'Amico et al. Adapting Teaching Strategies in a Learning Environment on WWW. In: World Conference of the WWW, Internet \& Intrane $t, 3 ., 1998$, Orlando. Charlottesville: Aace, 1998.

L. Giraffa, R. Viccari. The Use of Agents Techniques on Intelligent Tutoring Systems. In: Proceedings do International Conference of the Chilean Computer Science Society, Antofagasta, Chile: IEEE, 1998.

L. M. M. Giraffa. Uma Arquitetura de Tutor Utilizando Estados Mentais. Porto Alegre: CPGCC/UFRGS, 1999. Tese de Doutorado.

D. Goleman. Emotional Intelligence, New York: Bantam Books, 1995.

C. E. Izard. Emotion-cognition relationships and human development. In C.E. Izard, J. Kagan, \& R.B. Zajonc (Eds.). Emotions, cognition, and behavior. New York: Cambridge University Press. pages 17-37, 1984.

P. A. Jaques, R. Viccari. A BDI Approach to Infer Student's Emotions. In: Proceedings do IX Ibero-American Conference on Artificial Intelligence, Puebla, Mexico, 2004.

C. Martinho et al. A Cognitive Approach to Affective User Modeling. In: A. Paiva (Ed.). Affective Interactions - Towards a New Generation of Computer Interfaces. Berlin: Springer, 2000. p. 64-75. (Lecture Notes in Computer Science, 1814).

J. Meece, W. McColskey. Improving Student Motivation. Serve, 2001.

M. C. Móra et al. BDI models and systems: reducing the gap. In: Proceedings do Agents Theory, Architecture and Languages Workshop, Canarias. London: Springer-Verlag, 1998.

A. Ortony, G. Clore, A. Collins. The cognitive structure of emotions. Cambridge, UK: Cambridge University Press, 1988. 
J. Piaget. Les relations entre l'intelligence et l'affectivité dans le developpement de l'enfant. B. Rimé, K. Scherer (Eds.) Les Émotions. Textes de base en psychologie. Paris: Delachaux et Niestlé. pages 75-95, 1989.

R. Picard. Affective Computing. Cambridge: MIT Press, 1997.

R. Picard. An Interview with Rosalind Picard, Author of "Affective Computing". In: A. Paiva (Ed.). Affective Interactions - Towards a New Generation of Computer Interfaces. Berlin: Springer, 2000. p. 219-227. (Lecture Notes in Computer Science, 1814).

P. Pintrich et al. (1991) A Manual for the Use of the Motivated Strategies for Learning Questionnaire. TR 91-B-004. The Regents of the University of Michigan.

F. de Rosis. Toward Merging Cognition and Affect in HCI. Applied Artificial Intelligence, Philadelphia, v. 16, n. 7-8, p. 487-494, 2002.

K. Scherer. Appraisal Theory. In: T. Dalgleish, M. Power (Ed.) Handbook of Cognition and Emotion. New York: John Wiley \& Sons, 1999.

R. Silveira, R. Vicari. JADE - Java Agents for Distance Education Framework: An Agent Oriented Modeling Approach for Distributed Intelligent Learning Environment Projects. In: International Conference on Information and Communication Technologies in Education, 2002, Badajoz.

Sun. Custom
Networking.

http://java.sun.com/ docs/books/tutorial/networking/sockets/, 2003.

A. de Vicente e H. Pain. Motivation Diagnosis in Intelligent Tutoring Systems. In: International Conference on Intelligent Tutoring Systems, 4., San Antonio. Berlin: Springer, 1998. p. 86-95. (Lecture Notes in Computer Science, 1452).

L. Vygotsky. Thought and Language. Cambridge, MA: MIT Press, 1962. 